CATALAN REVIEW

Catalan Review

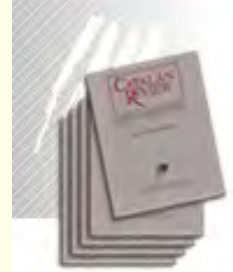

You are accessing the Digital Archive of the Catalan Review Journal.

By accessing and/or using this Digital Archive, you accept and agree to abide by the Terms and Conditions of Use available at http://www.nacs-

catalanstudies.org/catalan review.html

Catalan Review is the premier international scholarly journal devoted to all aspects of Catalan culture. By Catalan culture is understood all manifestations of intellectual and artistic life produced in the Catalan language or in the geographical areas where Catalan is spoken. Catalan Review has been in publication since 1986 .
NORTH

AMERICAN

CATALAN

SOCIETY
Esteu accedint a l'Arxiu Digital del Catalan Review

A l' accedir i / o utilitzar aquest Arxiu Digital, vostè accepta i es compromet a complir els termes i condicions d'ús disponibles a http://www.nacs-

catalanstudies.org/catalan review.html

Catalan Review és la primera revista internacional dedicada a tots els aspectes de la cultura catalana. Per la cultura catalana s'entén totes les manifestacions de la vida intel lectual i artística produïda en llengua catalana o en les zones geogràfiques on es parla català. Catalan Review es publica des de 1986.

\title{
Variació condicionada: aspectes qualitatius i quantitatius Maria-Rosa Lloret
}

Catalan Review, Vol. XVII, number 2, (2003), p. 107-122 


\title{
VARIACIÓ CONDICIONADA: ASPECTES QUALITATIUS I QUANTITATIUS*
}

\author{
MARIA-ROSA LLORET
}

\section{ABSTRACT}

The goal of this paper is to show that, although variation sometimes affects a small number of items, it never is completely arbitrary. It is rather conditioned by the grammatical system of a language (qualitative factors) and the quantitative effects that this grammatical system causes when it applies to a specific lexicon. Examples are drawn primarily from the verbal system of Balearic Catalan. The analysis of the data further shows that, even though retrospectively it is possible to explain why variation occurs under certain circumstances, it does not seem possible to predict which change will inevitably take place in a given situation.

\section{ז. INTRODUCCIÓ}

$\mathrm{E}_{1}$ punt de partida d'aquest treball és mostrar que la variació, encara que només afecti un sol element lèxic, no és del tot arbitrària sinó que està restringida pel sistema gramatical (factors qualitatius) i pels efectes quantitatius que aquest sistema gramatical provoca en actuar en un determinat lèxic. Si bé és cert que en la configuració d'una llengua els efectes dels factors quantitatius sovint complementen els dels qualitatius, de vegades la relació entre ambdós factors reflecteix tensions que es manifesten en termes de variació. La situació resultant comporta l'existència de desenvolupaments específics i esporàdics, en el sentit que només afecten determinats elements lèxics, que perduren al costat dels desenvolupaments més sistemàtics i regulars que les llengües majoritàriament presenten. Les dades que analitzarem per il-lustrar aquest aspecte provenen de la morfologia verbal del balear.

L'esquema de l'article és el següent. En primer lloc (\$ II), mostrarem fins a quin punt són importants els factors paradigmàtics per explicar el comportament fonològic, sovint excepcional, de les formes verbals del català balear sense desinència vocàlica (aquest apartat

* Aquesta investigació ha comptat amb el suport del Departament d'Universitats, Recerca i Societat de la Informació de la Generalitat de Catalunya (forma part del grup de recerca $2001 S G R$ ooo04) i del Ministerio de Ciencia y Tecnologia (projecte HUM 2004-0r504/FILO) i del FEDER. Les dades són del Corpus oral dialectal (COD) de la Universitat de Barcelona (http://www.ub.edu/lincat). 
es basa en els resultats obtinguts en els treballs de Lloret, The phonological, Efectes). Després (\$III-VI), analitzarem els casos concrets que mostren formes alternatives en diferents varietats del balear per veure quin grau de desviació presenten aquestes formes respecte del comportament general de les formes verbals; i tot això amb la voluntat d'esbrinar quines implicacions i dependències hi ha entre determinats canvis, per què hi ha variació en determinats casos i en altres no i per què hi ha coses que passen i altres que no. Finalment ( $\$$ VII), presentarem les conclusions.

\section{FACTORS PARADIGMÃTICS EN LA FLEXIÓ VERBAL DEL BALEAR}

Com és sabut, el català insular presenta la particularitat, reminiscència del català antic, de tenir primeres persones del singular del present d'indicatiu mancades de desinència (català antic i català insular actual: pos, neg, port). En català insular, aquestes formes sense desinència s'han imposat en els verbs que tenen el radical acabat en grups consonàntics que normalment necessiten un element vocàlic de suport per a la sil-labificació, els quals es troben documentats amb vocal final en català antic fins i tot en textos d'autors balears (català antic, general: entre, compre; català insular actual: entr, compr). S'ha adduït que l'anivellament de les primeres persones del singular del present d'indicatiu cap a la desinència 'zero' històricament es va produir per evitar l'homofonia, provocada per la reducció vocàlica, entre la primera persona del singular i la tercera persona del singular del present d'indicatiu a la primera conjugació, que és la més nombrosa (jo entre i ell entra o jo compre i ell compra serien homòfones; en canvi, no ho són jo entr i ell entra o jo compr i ell compra). Aquesta situació es degué estendre per analogia a formes d'altres conjugacions en què el factor determinant, l'homofonia a causa de la vocal final, no era pertinent (cf. jo/ell umpl, i també tu umpls). ${ }^{\mathrm{I}}$ El factor primer adduït és, doncs, de tipus qualitatiu (l'homofonia); el segon factor adduït és, en canvi, de tipus qualitatiu i quantitatiu (l'analogia, de la primera conjugació, més nombrosa, cap a les altres dues, menys nombroses). No ha passat pas desapercebut als estudiosos, però, la singularitat que l'opció triada pel català insular vagi en contra de la naturalitat fonològica (en el sentit que resten formes amb grups consonàntics excepcionals) i morfològica (en el sentit que la forma més marcada, la primera del singular, resta sense marca explícita de flexió). ${ }^{2}$

I. Alguns dels treballs que han dissertat sobre aquesta qüestió són Moll $54-56$, Pérez Saldanya $134-35$ i els més específics d'Alsina, Casanova i Wheeler.

2. D'acord amb els treballs clàssics de Benveniste, en aquest estudi s'assumeix que 
Sense menysprear la importància que l'homofonia $-\mathrm{i}$ posterior analogia- pugui haver tingut en l'evolució del català balear, per copsar l'abast real de l'homofonia és important tenir en compte el comportament de les persones del singular pel que fa a fenòmens fonològics altres que la inserció vocàlica. El motiu principal és que aquestes formes presenten més solucions inesperades de les previstes respecte de la situació general, algunes de les quals han estat aplegades per Pons Moll en el volum XVI (181-97) d'aquesta revista. En concret, el català balear (i l'alguerès) no presenta elisió de $-n$ postvocàlica fínal en les primeres persones del singular del present d'indicatiu, en què la nasal forma part del radical, tot i ser mots aguts; i en aquest cas l'homofonia no pot ser-ne la causa determinant: jo man, jo fren, jo perdon vs. ell mana, ell frena, ell perdona; cf. formes nominals com mà, fre, perdó. A més, en el conjunt del català la nasal no es perd en les terceres persones del singular del present d'indicatiu de conjugacions no primeres, que tampoc no presenten desinència vocàlica (ell roman, ell entén, ell pon), ni s'elideix quan és la marca de tercera persona del plural, encara que la forma verbal sigui aguda (cantaran, fan). Així mateix, el català balear (i l'alguerès) no presenta elisió de $-r(+s)$ postvocàlica final en les formes verbals de singular agudes del present d'indicatiu, en què la ròtica forma part del radical: jo mir, jo oper (cf. ell mira, ell opera) i també jo/ell mor, tu mors; cf. altres formes amb elisió, verbals, com ara les infinitives mira $(r)$, opera $(r)$, mori $(r)$, i nominals, com ara cla $(r) s$, carre $(r) s, p o(r) s$ i fins i tot $m a(r) s, o(r) s$ en mallorquí, on l'elisió de $-r(+s)$ final és més sistemàtica que en altres varietats. També aquí, en el conjunt del català, la ròtica es manté quan va seguida de s no desinencial: dispers, curs, dors. En cap dels casos anteriors, l'homofonia tampoc no justifica el manteniment de la ròtica.

la tercera persona del singular és no marcada respecte de la primera, tant en l'àmbit de la morfologia verbal com en l'àmbit de la morfologia pronominal. Els problemes morfofonològics que provocà, en català antic, la manca de desinència vocàlica han estat analitzats des de diferents punts de vista (veg. Pérez Saldanya cap. 8): $a$ ) homofonia amb altres formes verbals, $b$ ) contraiconicitat entre la primera persona del singular i la tercera persona del singular del present d'indicatiu en la primera conjugació, c) manca d'uniformitat desinencial en les primeres persones del singular del present d'indicatiu de totes les conjugacions, $d$ ) manca d'uniformitat sil-làbica entre la primera i la tercera persona del singular del present d'indicatiu en totes les conjugacions i e) manca d'unitormitat entre verbs sense desinència vocàlica i verbs amb -e dins la mateixa conjugació. Tot $\mathrm{i}$ això, en el canvi concret del català insular cap a una única forma sense desinencia vocàlica malgrat problemes de sil-labificació i homofonies de persona en verbs de les conjugacions segona i tercera, el factor determinant és $a$ ), o bé $c$ ) combinat amb $a$ ), o bé e) combinat amb els anteriors; en aquest cas, els factors c) i e) resoldrien el problema de naturalitat esmentat anteriorment. (Veg. Pérez Saldanya I $44-46$ per a una valoració detallada del pes de cada un d'aquests factors en l'evolució de la primera persona del singalar del present d'indicatiu en els diferents dialectes del catalâ.) 
Una solució alternativa i global als fenòmens excepcionals esmentats és apel-lar a la uniformitat paradigmàtica (o anivellament) -i no a l'homofonia (o contrast paradigmàtic)-, tal com es proposa a Lloret (The phonological, Efectes). ${ }^{3}$ Des d'aquest punt de vista, la manca de vocal final en les primeres persones anivella interparadigmàticament totes les desinències de les primeres persones del singular del present d'indicatiu (desinència 'zero' en totes les conjugacions); la manca de vocal final en la segona i tercera persona del singular del present d'indicatiu de les conjugacions segona i tercera anivella interparadigmàticament les desinències d'aquestes conjugacions (desinència $+s i$ 'zero'), $i$, en tots dos casos, la manca de vocal anivella intraparadigmàticament les formes superficials del radical verbal, perquè un cop manllevades les desinències morfològiques totes les formes superficials de cada radical verbal acaben terminant en consonant. La manca de vocal de suport evita l'al.lomorfia intraparadigmàtica dels radicals superficials (entre compr i compre) en el benentès que en les formes superficials, en què tots els elements han d'estar incorporats a l'estructura prosòdica, la vocal de suport s'adscriuria prosòdicament al radical, La vocal de suport no s'adscriuria prosòdicament a la desinència morfològica per no interferir amb els elements de flexió, que formen classes tancades i són més estables (veg. Lloret, Efectes). Cal notar que aquesta interpretació allomòrfica és diferent de la que proposa, des del punt de vista històric, Alsina (roz): Alsina considera que l'al-lomorfia que s'evità fou la interparadigmàtica (el fet que uns verbs no presentessin cap vocal al darrere, com cant, $\mathrm{i}$ altres sí, com compre), mentre que nosaltres proposem, des del punt de vista sincrònic, que l'al-lomorfia que s'evita és la intraparadigmàtica (entre compr i compre). Coincidim amb Alsina, però, a l'hora d'interpretar aquest fet com una complicació fonològica que aconsegueix eliminar l'al-lomorfia (i, de retruc, mantenir el contrast entre la primera persona del singular i la tercera persona del singular del present d'indicatiu en els verbs, majoritaris, de la conjugació primera).

La uniformitat intraparadigmàtica dels radicals verbals també explica de manera simple la inhibició sistemàtica de l'elisió de $-n$ i $-r(+s)$ finals en les formes verbals de singular agudes: $-n \mathrm{i}-r$ es mantenen quan formen part del radical verbal; es poden elidir, en canvi, quan formen part de la desinència morfològica (com en el cas del morf d'infinitiu). Aquesta és una altra complicació fonològica que evita l'al-lomorfia superficial dels radicals verbals (entre ma i man o entre

3. Per a un resum i valoració d'anàlisis anteriors no paradigmàtiques sobre el comportament fonològic excepcional de les formes verbals de primera persona del singular del present d'indicatiu en català balear des del punt de vista sincrónic, veg., per exemple, Pons Moll. 
mi i mir, per exemple).4 Òbviament, la uniformitat intraparadigmàtica dels radicals verbals no és sempre total: hi ha fenòmens fonològics regulars, sense excepció, que actuen malgrat crear una certa heterogeneïtat superficial. Es el cas, per exemple, de l'ensordiment d'obstruents finals, que crea alternances entre segments sords i sonors en el radical (cf. tro[p], trobes, troba...; ne[k], negues, nega...; i també cla[f], claves, clava... en algunes varietats del balear).

No obstant la situació general d'uniformitat paradigmàtica que acabem d'esmentar, per a alguns verbs hi ha un conjunt de paradigmes alternatius en diferents varietats del balear que cal revisar perquè són indicatius dels factors que condicionen la variació respecte de la situació regular general. Els canvis implicats afecten la presència de la vocal de suport (\$ III), l'elisió de $-r(+s)$ final (\$ IV), l'elisió de $-n$ final (\$ V) i l'alternança de la fricativa labial sonora (\$ VI).

\section{VARIACiÓ RELATIVA A LA VOCAL DE SUPORT}

L'absència de la vocal de suport - e en les primeres persones del singular del present d'indicatiu és del tot sistemàtica (uniformitat intraparadigmàtica $\mathrm{i}$ interparadigmàtica) en tot el català balear. Ara bé, en la segona i tercera persona del singular dels verbs de les conjugacions no primeres hi ha una certa variació dialectal. Els verbs d'aquestes conjugacions que presenten, en principi, problemes de sil-labificació si no afegeixen la vocal de suport són pocs: córrer, obrir i omplir.

En el cas d'omplir, només s'han constatat formes sense vocal de suport tant a la primera persona del singular com a la segona i tercera persona del singular: umpl, umpls, umpl. En canvi, els altres dos verbs presenten paradigmes alternatius: al costat dels paradigmes corr, corrs, corr i obr, obrs, obr també s'han documentat els paradigmes corr, corres, corre (general a Menorca, Eivissa i Formentera i a zones de Mallorca com Palma i Esporles); corr, corrs, corre (a Sóller); corrc, corrs, corr (a zones de Mallorca com Manacor i Felanitx); abr, obres, obre (a Menorca), i obr, obris, obri (a Eivissa i Formentera i majoritàriament a Mallorca). D’aquests paradigmes alternatius, el format per $o b r$, obris, obri és documentat des d'antic, amb vocal $i$ etimològica ("OPERIO) també present a la tercera persona del plural: obrin.5 El fet

4. En aquest treball, ens limitem a l'estudi de la flexió verbal. Per veure els motius pels quals l'elisió de $-n \mathrm{i}-r(+s)$ presenta una abast diferent en els casos de la flexió nominal, veg. Lloret, The phonological, Efectes; també són indicatives les observacions fetes a $\$$ VI respecte del comportament de $-/ \mathrm{v} /$.

5. Aquest paradigma en $-i$ (en què $i$ soluciona els problemes de sil-labificació de la segona i tercera persona del singular), també el trobem en valencià, on s'ha generalizzat 
que en cap subdialecte balear s'hagin generalitzat formes amb - e en el verb omplir mostra que les solucions amb-e de córrer i obrir no són regulars sinó marginals i que, per tant, l'explicació sincrònica general més adequada per als casos de manca de terminació vocàlica malgrat problemes de sil-labificació continua essent la que apel-la a la uniformitat paradigmàtica i no la que recorre al contrast. La uniformitat paradigmàtica també es mostra més adequada que no pas el contrast a l'hora de donar compte de l'existència del paradigma obr, obris, obri, obrin, que és irregular des del punt de vista de les desinències: jo obre ( $\mathrm{amb}$ vocal de suport) i ell abri (amb desinència irregular) no serien homòfones $i$, per tant, el contrast paradigmàtic no pot justificar l'absència real de la vocal de suport en la primera persona (jo obr vs. ell obri); però la uniformitat paradigmàtica, sí.

$\mathrm{Amb}$ tot, $\mathrm{cal}$ reconèixer en algun cas aillat de les conjugacions minoritàries la força -antiga- de la pressió del contrast paradigmàtic. Així s'explica l'aparició, excepcional, de la vocal de suport només a la tercera persona del singular del present d'indicatiu en el paradigma solleric corr, corrs, corre: la uniformitat paradigmàtica és responsable de l'absència de la vocal en la primera i segona persona (corr, corrs) però la voluntat de contrastar la primera i la tercera persona del singular del present d'indicatiu (aconseguit, de retruc, a la primera conjugació per la manca de terminació vocàlica en la primera persona) justifica l'aparició d'aquesta vocal en la tercera persona (ell corre). La fonologia regular (la inserció de la vocal de suport) actua en la forma menys marcada (la tercera persona), tal com es prediu des del punt de vista de la naturalitat fonològica i morfològica.

El contrast provoca al-lomorfia intraparadigmàtica del radical (corr a la primera persona vs. corre a la tercera persona) i, per consegüent, no és estrany que, un cop trencada la uniformitat intraparadigmàtica, la fonologia regularitzi altres formes mal formades sil-làbicament. Aquest és el cas dels paradigmes corr, corres, corre i obr, abres, obre (generals a Menorca, Eivissa i Formentera i a zones de Mallorca), amb vocal de suport a la segona i a la tercera persona. L'observació rellevant aquí és que la vocal de suport mai no apareix només en la segona persona del singular del present d'indicatiu (és a dir, no existeixen paradigmes com corr, corres, corr o com obr, obres, $o b r)$, perquè el sistema no admet trencar la uniformitat intraparadigmàtica sense resoldre el contrast.

Aquesta interpretació dels fets ve reforçada pels casos que presenten algun tipus d'al-lomorfia subjacent, o lèxica: si el contrast paradigmàtic és satisfet morfològicament per al-lomorfia lèxica, mai no

a un altre verb de la tercera conjugació amb problemes de sil labificació: omplir. En valencià, aixi, tenim òbric, obris, obri i omplic, omplis, ompli. 
trobem ni terceres ni segones persones regularitzades amb la vocal de suport. Així, existeix el paradigma corrc, corrs, corr (a Manacor i Felanitx, per exemple), amb una primera persona amb element velar que desfà l'homofonia amb la tercera persona, sense que l'efecte reparador de la vocal de suport aparegui en cap forma verbal (no s'ha constatat l'existència d'un paradigma del tipus corrc, corres, corre, per exemple). La nostra explicació preveu justament aquesta relació implicativa de les formes verbals: el factor primer (la uniformitat paradigmàtica) proveeix formes sense vocal de suport, tant si hi ha homofonia entre la primera i la tercera persona del singular com si no n'hi ha; el factor secundari (el contrast paradigmàtic) fa possible l'existència, marginal, de terceres persones del singular (i, de retruc, de segones persones del singular) amb vocal de suport en les classes minoritàries (en el sentit de poc nombroses) de la segona i tercera conjugació.

En aquestes conjugacions, a més, la pressió interparadigmàtica de les desinencies és menor en la segona i tercera persona del singular del present d'indicatiu que no pas en la primera persona del singular, ja que la classe majoritària (la primera conjugació) presenta desinències vocàliques en aquestes dues formes verbals (-es, $-a$, com a entres, entra) mentre que les classes minoritàries presenten regularment desinències sense vocal $(-s$, 'zero', com a dorms, dorm).

La presència de desinències vocàliques en la conjugació majoritària també afavoreix l'existència de terminacions vocàliques en els verbs de les classes minoritàries que presenten problemes de sil-labificació tant en la tercera persona del singular del present d'indicatiu (en què a mếs $s$ 'acompleix el contrast paradigmàtic) com en la segona persona del singular del present d'indicatiu (en què el contrast paradigmàtic és irrellevant).

La situació descrita es resumeix en l'esquema $\mathrm{I}$ (veure pàgina següent). En aquest esquema, 'Fonologia irregular' fa referència a l'absència de vocal de suport malgrat deficiències en la sill-labificació; 'Fonologia regular' fa referència a la presència de vocal de suport per motius sillà̆bics. 
Esquema i. Variació relativa a la vocal de suport

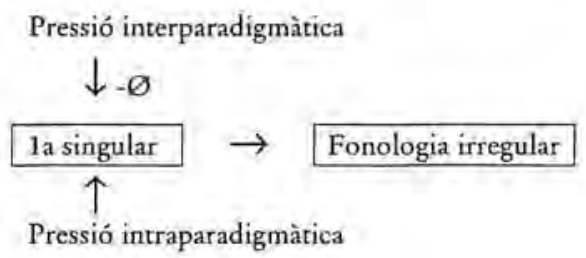

(Pressió interparadigmàtica)

- Totes les conjugacions:

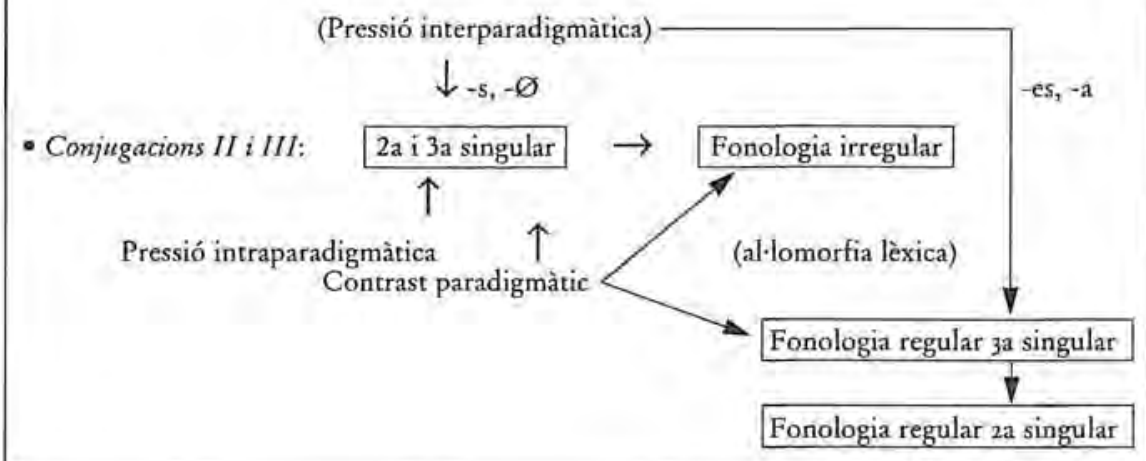

\section{VARIACIÓ RELATIVA A LA BATEGANT FINAL}

El manteniment de $-r$ postvocàlica final en les primeres persones del singular del català balear és del tot sistemàtica (mir, prepar, oper, mor) $\mathrm{i}$ irregular, ja que esperaríem l'elisió d'aquesta consonant pel context en què apareix (final de mot agut). L'únic verb que el català té de conjugacions minoritàries $\mathrm{amb}$ radical $\mathrm{amb} \rightarrow r$ final (i sense segment incoatiu) és morir. En el paradigma d'aquest verb, la ròtica també es manté excepcionalment en la segona i tercera persona del singular en català general: tu mors, ell mor (cf. els elements nominals $d u(r), d u(r) s$ o $p o(r), p o(r) s$, amb elisió de la ròtica en el mateix context).

Com en el cas de les vocals de suport, la uniformitat intraparadigmàtica dels radicals verbals provoca un comportament fonològic irregular (el manteniment de $-r$ final a mor, mors, mor), però també aquí trobem paradigmes alternatius; mor, mors, mo(r), amb elisió regular de $-r$ a la tercera persona del singular (a Palma, per exemple); morc, mors, mor, amb presència irregular del segment velar a la primera persona del singular i manteniment de $-r$ en totes les formes (a zones de Mallorca com sa Pobla i Felanitx); muir, mors, mor, amb un al-lomorf radical diferent a la primera persona del singular a causa 
d'una metàtesi històrica en la forma etimològica MORIO i manteniment de $-r$ en totes les formes (a zones de Mallorca com Pollença, Binissalem i també Felanitx).

Els paradigmes alternatius de morir segueixen el mateix patró que hem trobat abans per als casos relacionats amb l'aparició, excepcional, de la vocal de suport a córrer i obrir. Així, si la morfologia proporciona una solució lèxica que resol l'homofonia, se segueix mantenint la ròtica per respectar també la uniformitat intraparadigmàtica radical relativa a $-r$ (morc, mors, mor). Si la morfologia radical proporciona un al-lomorf que resol l'homofonia, la ròtica també es manté per respectar la uniformitat intraparadigmàtica radical en relació amb la presència d'aquest segment (muir, mors, mor). Si la fonologia regular provoca, excepcionalment, l'elisió de la ròtica, ho fa per promoure el contrast entre la primera i la tercera persona del singular del present d'indicatiu ( $m o r$, mors, mo( $r$ ), en què l'elisió afecta la persona menys marcada, és a dir, la tercera del singular). I només existeixen, i no per atzar, aquestes relacions implicatives. Així, en cap cas no s'elideix la $-r$ de la tercera persona del singular si la primera persona és morc o muir, perquè el contrast ja s'ha acomplert mitjançant l'al-lomorfia lèxica (no existeixen, per exemple, les combinacions morc, mors, $m o(r)$ o muir, mors, mo(r)); ni apareix l'element velar si la primera persona del singular presenta un al-lomorf diferent, perque també aquí el contrast ja s'ha satisfet (no existeix, per exemple, la combinació muirc, mors, mor).

En el paradigma mor, mors, mo(r), la uniformitat intraparadigmàtica del radical respecte de la presència o no de la consonant final es trenca en benefici del contrast paradigmàtic. Cal assenyalar que l'elisió de $-r$, a diferència de la presència de la vocal de suport, mai no afecta la segona persona del singular (no existeix la combinació mor, $m o(r) s, m o(r)$, però en canvi sí que existeix la combinació obr, obres, obre i corr, corres, corre). Tal com hem dit abans, a obrir i córrer la presència de la vocal de suport és afavorida pel fet que les formes resultants (obres, corres) s'assemblen, superficialment, a les de la classe majoritària, que tenen desinència vocàlica (compres, entres); en canvi, no s'estableix la mateixa relació pel que fa a l'elisió de $-r$ a morir i, per tant, la fonologia regular (l'elisió de $-r$ ) es limita a actuar en la tercera persona del singular del present d'indicatiu per mor del contrast.

L'esquema 2 resumeix les implicacions descrites. En aquest esque$\mathrm{ma}$, 'Fonologia irregular' fa referència al manteniment $\mathrm{de}-r(+s)$ final; 'Fonologia regular' fa referència a l'elisió de $-r(+s)$ final. 
Esquema 2. Variació relativa a la bategant final

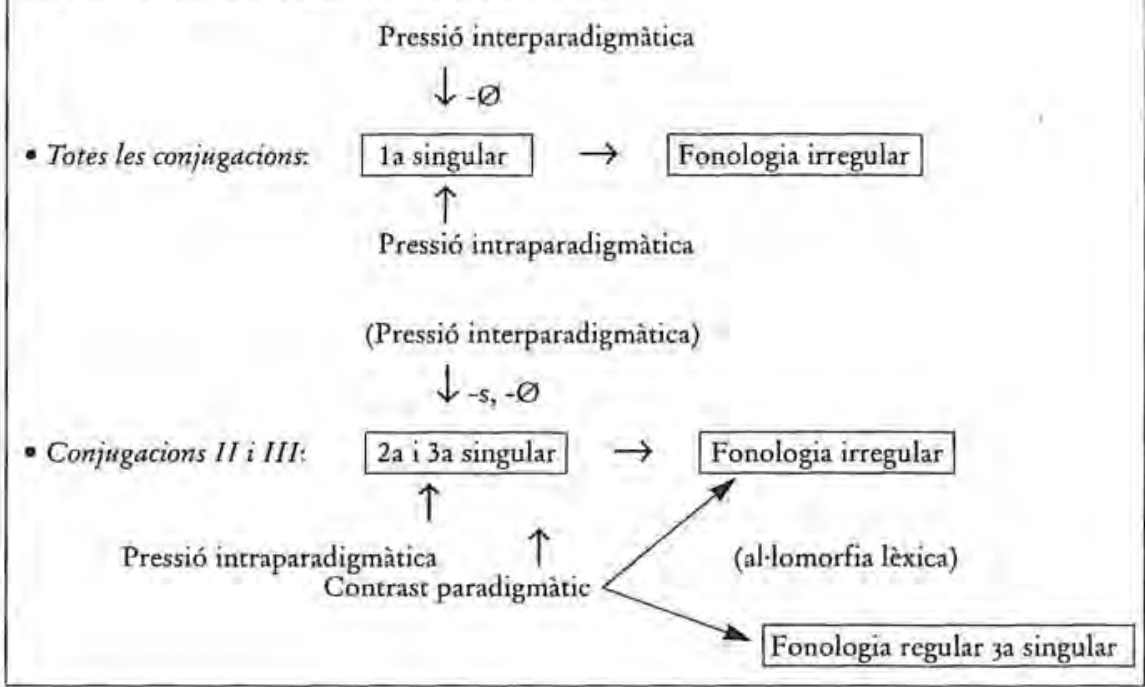

\section{VARIACIO RELATIVA A LA NASAL ALVEOLAR FINAL}

El manteniment de la nasal alveolar postvocàlica final en les primeres persones del singular del català balear és del tot sistemàtica (man, fren, perdon) i irregular, ja que esperaríem l'elisió d'aquesta consonant pel context en què apareix (final de mot agut). Els verbs de la conjugació segona amb radical amb $-n$ també presenten, en el conjunt del català, manteniment sistemàtic irregular de la nasal en la tercera persona del singular (entén, pren, pon). En ambdós casos la uniformitat intraparadigmàtica preveu aquesta situació. A més, en el cas dels verbs de la conjugació minoritària també es justifica, des d'aquesta perspectiva, el manteniment sistemàtic de la nasal, ja que el contrast entre la primera persona del singular i la tercera persona del singular del present d'indicatiu sempre s'acompleix a causa de la presència del segment velar en la primera persona: entenc, entens, entén; prenc, prens, pren; ponc, pons, pon. No es recorre, doncs, a l'elisió de $-n$ perquè el contrast ja s'aconsegueix d'altra manera. L'esquema 3 resumeix la situació anterior. Aquí, 'Fonologia irregular' fa referència al manteniment de $-n$ final. 
Esquema 3. Variació relativa a la nasal alveolar final

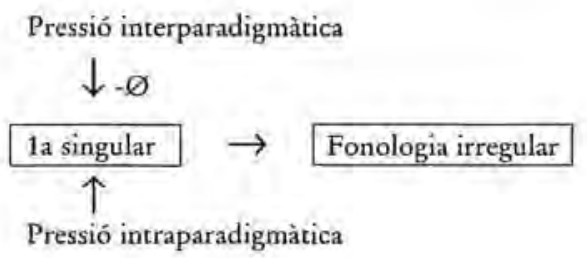

(Pressió interparadigmàtica)

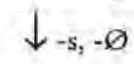

- Conjugacions II i III:

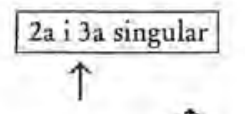

Pressió intraparadigmàtica

Contrast paradígmàtic

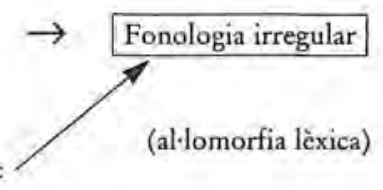

Hi ha dos verbs més de conjugacions minoritàries amb radical amb $-n$, tenir i venir (i derivats), de conjugació mixta segona i terce$\mathrm{ra}$, que mereixen un comentari a part. En aquest cas, la nasal s'elideix en el conjunt del català a la tercera persona del singular (té i ve), i aixõ no és fortuït. S'hi produeix perquè són verbs irregulars, $i$ en aquestes circumstàncies la pressió uniformadora de radicals queda inactiva, com si la regularicat fonològica (elisió de $-n$ en el radical, excepcional en la flexió verbal) compensés la irregularitat morfològica flexional. ${ }^{6}$

\section{VARIACIÓ RELATIVA A LA FRICATIVA LABIAL SONORA FINAL}

L'últim cas relacionat amb la variació que analitzarem és el dels verbs amb fricativa labial sonora $(/ \mathrm{v} /)$ postvocàlica final en el radical. En català balear, els verbs de la primera conjugació mostren, en general, ensordiment d'aquesta obstruent final en la primera persona del sin-

6. Moltes varietats del balear presenten en aquests dos verbs una altra peculiaritat: mantenen radical uniforme amb e (tenc, tendré, tendria, tengui, tengut, tenguent; venc, vendré, vendria, véngui, vengut, venguent) en lloc de l'alternança $e \sim i$ que presenten altres varietats (ef. tinc, tindré, tindria, tingui, tingut, tinguent; vinc, vindre, vindria, ving $u i$, vingut, vinguent). En aquest cas, l'homogeneitat morfològica relativa al timbre de la vocal de radical (que acaba tenint només $e$ ) compensa les altres irregularitats. 
gular (lle[f], pro[f], cla[f] de llevar, provar, clavar). D'acord amb les observacions de Bibiloni (Elisiô 281), aquestes solucions són modernes i han substituit les més antigues amb semivocal (lle[w], pro[w], $c l a[w])$, que s'adiuen amb l'alternança regular $[\mathrm{w}] \sim[\mathrm{v}]$ dels dialectes que tenen $/ \mathrm{v} /$ (cf. escla[w] escla[v]itud, no[w] no[v]a). Hi ha parlants de la generació més gran que mantenen, en alguns verbs, aquestes formes més antigues (lle[w], pro[w] però cla[fJ). I també hi ha sectors joves de la població que han perdut la fricativa sonora /v/ i realizzen, en aquests verbs, l'oclusiva sorda, derivada de /b/ (lle $[p]$, pro[p] i cla $[p]$, de $l l e / b /$, pro/b/ i cla/bl, com $s a[p]$, de $s a / b /)$. Aquest darrer grup manté l'alternança $[w] \sim[\beta]$ en els altres casos, talment com fan els dialectes que presenten $/ \mathrm{b} /$ en lloc de $/ \mathrm{v} /$ (escla[w] escla[ß]itud, no[w] no[ß]a).7 Resumim, a continuació, els quatre estadis idencificats pel que fa a la posició final de les formes objecte d'aquest estudi:

- Estadi $E_{\mathrm{S}} / \mathrm{v} / \mathrm{s} \quad-[\mathrm{w}]$ a morfologia nominal i verbal

- Estadi $2+/ \mathrm{v} /: \quad-[\mathrm{w}]$ a morfologia nominal

$-[\mathrm{w}]$ o - [f] a morfologia verbal (ta pers. sing.), determinat lèxicament

- Estadi 3: /v/: $\quad$-[w] a morfologia nominal

-[f] a morfologia verbal (ta pers. sing.)

- Estadi \&:/v/>/b/: -[w] a morfologia nominal

-[p] a morfologia verbal (1a pers. sing.)

Les dades del balear relacionades amb el comportament de /v/ en posició final són interessants perquè il-lustren la controvèrsia entre la perspectiva neogramàtica sobre el canvi lingüístic (basada en el canvi fonètic regular, que afecta globalment tots els mots, de cop, que compleixen les condicions per al canvi) i perspectives més recents basades en la difusió lèxica (és a dir, canvis que s'estenen de mot a mot i no globalment). Pel que fa a l'alternança antiga [w] [v], sembla que no hi ha cap motiu que afavoreixi el mecanisme de difusió lèxica (noteu que l'alternança afectà per igual la flexió nominal i la verbal). Ara bé, en la variació actual, en què [v] intervocàlica alterna amb [w] o amb [f] en posició final, la teoria de la difusió lèxica sembla confirmar-se. En la bibliografia actual, hi ha evidència prou clara per afirmar que ambdós tipus de canvis són actius i productius (Labov cap. 15-17). La nostra visió dels fets és que la difusió lèxica no és el mecanisme bàsic del canvi lingüístic però pot aparèixer juntament amb els canvis regulars,

7. En tots els casos, es manté inalterada l'alternança [w] [v] (o [w] [ß]) en els verbs amb radical amb semivocal labial, com moure (cf. tu mous, ell mou vs. movia $\mathrm{i}$ també moven, en mallorquí). Els verbs amb radical amb semivocal labial final, és a dir, els que tenen infinitius en -ure (tant els que provenen de labial etimològica com els que no), presenten altres complicacions que queden fora de l'abast d'aquest estudi (veg. Bibiloni, La llengua 137). 
i el nostre interès és esbrinar quins són els factors que afavoreixen la difusió.

Les realitzacions - $[\mathrm{w}]$ de les primeres persones del singular del present d'indicatiu són exponents d'un canvi regular, condicionat per la posició sil-làbica que ocupa el segment labial: en posició de coda sil-làbica apareix com a semivocal (lle[w], pro[w], cla[w]); en posició postvocàlica d'obertura sil-làbica apareix com a fricativa (lle[v]a, pro[v]a, cla $[v] a)$. Aquest patró s'adiu amb l’observació universal segons la qual són preferibles les obertures amb grau de sonicitat baix, per diferenciar-se clarament, dels nuclis vocàlics, $i$ les codes amb grau de sonicitat alt, per aconseguir una distensió sil-làbica gradual (Clements 305). L'estadi I reflecteix, doncs, un canvi fonètic regular i global en el sistema. Aquesta situació, però, es distorsiona en l'estadi 2, quan les primeres persones del singular d'alguns verbs passen a ser realitzades com a fricatives sordes. 1 les causes són fonètiques i paradigmàtiques.

Des del punt de vista perceptual, s'ha argumentat que les modificacions de sonoritat són menys importants (perquè creen menys dissemblança entre les formes) que no pas les modificacions de sonicitat, i per tant són universalment preferides (Steriade 32 ). ${ }^{8}$ Ara bé, si el motiu del canvi fos merament fonètic, esperaríem que el canvi afectés per igual la flexió nominal i la verbal. Però aquest no és el cas, ja que en la flexió nominal es manté sistemàticament l'alternança [w] [v] (esclau esclava, nou nova). I això és així perquè la motivació fonètica s'imbrica amb la morfològica. Els paradigmes flexius verbals contenen una quarantena de formes simples; en canvi, els paradigmes flexius nominals contenen dues formes en el cas dels substantius (diferenciades pel nombre) i quatre en el cas dels adjectius (diferenciades pel gènere $i$ pel nombre). En els subparadigmes verbals que s'estableixen, cada temps verbal té sis formes personals (excepte l'imperatiu, que en té cinc). En els subparadigmes nominals, cal diferenciar les formes relacionades per nombre (comunes a substantius $i$ adjectius) $i$ les relacionades per gènere (en els adjectius i en alguns substantius). En els subparadigmes nominals, la identitat del segment labial es manté sempre dins de cada subparadigma amb gènere comú (ou, ous; esclau, esclaus; nou, nous; esclava, esclaves; nova, noves). En els subparadigmes verbals, la identitat del segment labial, en tant que fricatiu, es manté a costa d'una innovació en el sistema (l'ensordiment de /v/ postvocàlica final), que s'adiu amb el fenomen regular d'ensordiment d'obstruents finals. No és fortuït, doncs, que la variació hagi aparegut en les

8. En aquest cas, l'alguerès presenta, en la flexió verbal, el canvi previst cap a l'ensordiment (llelf], prolf], cralf] i també escrilff), que és el que provoca menys dissemblança intraparadigmàtica en la flexió verbal. 
formes verbals i no en les nominals. En l'estadi 2, aquest canvi és de progressió lèxica, però només dins els elements verbals per satisfer millor la uniformitat intraparadigmàtica. En l'estadi 3, aquest canvi s'ha generalitzat dins la flexió verbal, la qual cosa atorga estabilitat als paradigmes verbals regulars. La difusió del canvi no s'ha produït, doncs, de forma indiscriminada (com preveuen els defensors dels canvis per difusió lèxica), sinó que està condicionada pels efectes paradigmàtics.

L'estadi 4 ens confirma l'argumentació anterior. La substitució dràstica de $/ \mathrm{v} /$ per $/ \mathrm{b} /$, probablement provocada per causes externes, altera els resultats en la flexió verbal, on es regularitza l'alternança regular [p] [B] (lle[p] lle $[\beta] a$, pro $[p] \sim$ pro $[\beta] a$, cla $[p] \sim$ cla $[\beta] a)$, però no altera els resultats generals de les formes flexionades nominals del tipus [w] [ß] (escla[w] escla[ß]a, no[w] no[ß]a). La substitució d'un fonema per l'altre (de $/ \mathrm{v} /$ per $/ \mathrm{b} /$ ), doncs, no resulta en un canvi fonètic regular global (tal com es prediria des del punt de vista neogramàtic), sinó que queda limitada a determinades classes (i no a elements lèxics específics, tal com es prediria des de la perspectiva de la difusió lèxica).

L'esquema 4 resumeix els canvis relatius a les primeres persones del singular en relació amb les alternances pròpies de la resta del sistema.

\section{Esquema 4}

Evolució de la variació relativa a la fricativa labial sonora labial

IA PERS. SING. PRESENI INDICATIU

- Estadi i:

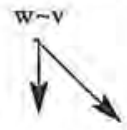

- Estadi 2 :

Pressió perceptual

Altres

$\mathrm{w} \sim \mathrm{v}$

condicionada paradigmàticament

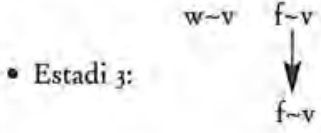

Difusió lèxica

$\mathrm{w} \sim \mathrm{v}$

Estabilització condicionada

paradigmàticament

w $\sim v$

- Estadi 4:

Substitució dràstica $v>b$

$P \sim B$

Cf. /b/ original:

$\mathrm{w} \sim \mathrm{B}$

$\mathrm{P} \sim \beta$

$p \sim \beta$ 


\section{CONClusió}

A la vista de les dades del català balear que acabem d'analitzar, cal admetre que alguns canvis van lligats a elements lèxics específics i que la seva propagació sembla esporàdica, tot i que acaba essent determinada per l'organització implicativa dels paradigmes. Però encara que retrospectivament puguem explicar els motius pels quals han aparegut en un determinat lloc del sistema i no en un altre $i$ els motius pels quals han provocat un determinat tipus de canvi i no uns altres, no sembla possible, de moment, predir quina serà la relació de forces entre els aspectes morfològics $\mathrm{i}$ els fonològics, ni entre els factors interns i els externs. Per això, en aquest treball ens hem acontentat a veure què ha passat $i$, si hem tingut encert, a explicar les raons per què ha passat aixíi no d'una altra manera.

MARIA-ROSA LLORET
UNIVERSITAT DE BARCELONA

\section{REFERËNCIES}

AtsINA, Alex. "Un aspecte de la morfologia històrica catalana: la primera persona del singular del present d'indicatiu". Llengua \& Literatura 3 (1988-89): 89-119.

BENVENISTE, Émile. "Structure des relations de personne dans le verbe". Problèmes de linguistique générale, $x$. Paris: Gallimard, 1946. 225-37.

BiBILONI, Gabriel. "La llengua dels mallorquins. Anàlisi sociolingüística". Tesi doctoral inèdita. U de Barcelona, 1983.

"Elisió de $-n \mathrm{i}-r$, distribució de les ròtiques $\mathrm{i}$ altres fenòmens consonàntics en el mot". Gramàtica del català contemporani. Dir. Joan Solà, Maria-Rosa Lloret, Joan Mascaró i Manuel Pérez Saldanya. Vol. t. Barcelona: Empúries, 2002. 271-85.

CASANOVA, Emili. "Gramàtica històrica i història de la llengua. A propòsit de l'evolució de la desinència de ra persona del present d'indicatiu". Actes del Segon Congrés Internacional de la Llengua Catalana. València: Institut de Filologia Valenciana, 1989. 343-57.

ClEmentS, G. N. "The role of the sonority cycle in core syllabification". Papers in Laboratory Phonology I. Between the Grammar and Physics of Speech. Ed. John Kingston i Mary E. Beckman. Cambridge: Cambridge UP, 1990. 283-333.

LABOV, William. Principles of Linguistic Change. Internal factors. Language in Society 20. Oxford: Blackwell, 1994. 
LLORET, Maria-Rosa. "Efectes col-laterals de la 'desinència' zero' en la flexió verbal algueresa". Estudis de Llengua i Literatura Catalanes 49. Miscel-lània Joan Veny 5. Barcelona: Abadia de Montserrat, 2004. 233-66.

"The phonological role of paradigms: The case of insular Catalan." Contemporary Approaches to Romance Linguistics (Selected papers from the $33^{\text {rd }}$ Linguistic Symposium on Romance Languages (LSRL), Bloomington, Indiana, April 2003. Ed. Julie Auger, J. Clancy Clements i Barbara Vance. Amsterdam: John Benjamins, 2004. 275-97. [Es pot consultar en línia a: ROA núm. 646-0304.]

Moll, Francesc de. El parlar de Mallorca. Biblioteca Bàsica de Mallorca 26. Mallorca: Moll, 1990.

Pérez Saldanya, Manuel. Del llatí al català. Morfosintaxi verbal bistòrica. Biblioteca Lingüística Catalana. València: U de València, 1998.

PONS MOLL, Clàudia. "Estructura sillàbica i processos fonològics en balear". Catalan Review 16. 1-2 (2001): 181-97.

STERIADE, Donca. "The Phonology of Perceptibility Effects: The PMap and its Consequences for Constraint Organization". Ms. UCLA, 200I.

WHEELER, Max W. "La primera persona del present d'indicatiu, pot haver-hi més a dir-ne?" Estudis de lingüistica i filologia oferts a Antoni M. Badia i Margarit. Vol. 2. Barcelona: Departament de Filologia Catalana (U de Barcelona), Abadia de Montserrat, 1995. $4 \mathrm{II}-25$. 